\title{
Increases in cAMP, MAPK Activity, and CREB Phosphorylation during REM Sleep: Implications for REM Sleep and Memory Consolidation
}

\author{
Jie Luo, Trongha X. Phan, Yimei Yang, Michael G. Garelick, and Daniel R. Storm \\ Department of Pharmacology, School of Medicine, University of Washington, Seattle, Washington 98195
}

The cyclic adenosine monophosphate (cAMP), mitogen-activated protein kinase (MAPK), and cAMP response element-binding protein (CREB) transcriptional pathway is required for consolidation of hippocampus-dependent memory. In mice, this pathway undergoes a circadian oscillation required for memory persistence that reaches a peak during the daytime. Because mice exhibit polyphasic sleep patterns during the day, this suggested the interesting possibility that CAMP, MAPK activity, and CREB phosphorylation may be elevated during sleep. Here, we report that cAMP, phospho-p44/42 MAPK, and phospho-CREB are higher in rapid eye movement (REM) sleep compared with awake mice but are not elevated in non-REM sleep. This peak of activity during REM sleep does not occur in mice lacking calmodulin-stimulated adenylyl cyclases, a mouse strain that learns but cannot consolidate hippocampus-dependent memory. We conclude that a preferential increase in cAMP, MAPK activity, and CREB phosphorylation during REM sleep may contribute to hippocampus-dependent memory consolidation.

\section{Introduction}

Sleep is an indispensable physiological state that naturally occurs in a wide variety of species (Campbell and Tobler, 1984; Cirelli and Tononi, 2008; Siegel, 2008). It is characterized by the reversible loss of consciousness and reduced motor activity. In terrestrial mammals and birds, sleep is further separated into rapid eye movement (REM) sleep and non-REM (NREM) sleep based on distinctive EEG/EMG measurements (Lesku et al., 2006; Allada and Siegel, 2008; Siegel, 2009). REM sleep is evidenced by rapid, low-voltage $\theta$ waves $(4-8 \mathrm{~Hz})$ in parallel with muscle atonia and rapid eye/whisker movements (Aserinsky and Kleitman, 1953). NREM sleep, however, is composed of stage 1,2 and slow-wave sleep (SWS) featuring low-frequency, large-amplitude $\delta$ waves (0.5-4 Hz) (Rechtschaffen and Kales, 1968).

Sleep has been strongly implicated in the off-line reprocessing of recently acquired memory (Stickgold, 1998; Walker and Stickgold, 2004; Stickgold, 2005; Marshall and Born, 2007; Diekelmann and Born, 2010; Hernandez and Abel, 2011). However, the

Received Oct. 25, 2012; revised March 1, 2013; accepted March 7, 2013.

Author contributions: J.L., T.X.P., and D.R.S. designed research; J.L., Y.Y., and M.G.G. performed research; J.L. analyzed data; J.L. and D.R.S. wrote the paper.

This work was supported by National Institutes of Health Grants NS 20498 and MH 073601. We thank members of the D.R.S. laboratory for critical reading of the manuscript and the W. M. Keck Center for Advanced Studies in Neural Signaling for imaging assistance.

The authors declare no competing financial interests.

Correspondence should be addressed to Dr. Daniel R. Storm, Department of Pharmacology, Mail Box 357750, Health Sciences Building, University of Washington, Seattle, WA 98195-7750. E-mail: dstorm@u.washington.edu.

T.X. Phan's present address: Picower Institute for Learning and Memory, Massachusetts Institute of Technology, 77 Massachusetts Avenue, Cambridge, MA 02139.

M. G. Garelick's present address: Center for Neural Science, New York University, 4 Washington Place West, New York, NY 10003

DOI:10.1523/JNEUROSCI.5018-12.2013

Copyright $\odot 2013$ the authors $\quad 0270-6474 / 13 / 336460-09 \$ 15.00 / 0$ mechanistic relationship between sleep and memory consolidation is undefined. In rodents, neuronal firings recapitulating those evoked by previous awake behavior have been detected in both REM sleep and NREM sleep (Wilson and McNaughton, 1994; Skaggs and McNaughton, 1996; Shen et al., 1998; Poe et al., 2000; Louie and Wilson, 2001; Ji and Wilson, 2007). These findings suggest the intriguing hypothesis that molecular cascades activated during memory acquisition may be recruited during subsequent sleep to promote memory consolidation.

Consolidation of hippocampus-dependent memory depends upon activation of the calmodulin-stimulated adenylyl cyclases, mitogen-activated protein kinase (MAPK), and cAMP response element-binding protein (CREB)-mediated transcriptional pathway (Bourtchuladze et al., 1994; Wu et al., 1995; Atkins et al., 1998; Blum et al., 1999; Wong et al., 1999; Athos et al., 2002; Pittenger et al., 2002; Sindreu et al., 2007). However, how longterm memory can endure for periods far exceeding the lifetimes of synaptic proteins produced during memory acquisition remains to be determined. Recent studies have revealed that the cAMP/MAPK/CREB pathway undergoes a circadian oscillation in area CA1 of the mouse hippocampus with peak activity during the daytime at ZT4 (zeitgeber time 4, 12:00 P.M.). Disruption of this signaling oscillation days after hippocampus-dependent memory is consolidated impairs the persistence of memory (Eckel-Mahan et al., 2008; Phan et al., 2011). This has led to the idea that hippocampus-dependent memories are maintained over extended periods of time by periodic reactivation of this memory consolidation pathway during the circadian cycle.

Because the cAMP/MAPK/CREB transcriptional pathway is maximal during the daytime when mice exhibit periods of wakefulness, REM sleep and NREM sleep, a critical question is whether or not this signaling pathway is activated during sleep. 
Here, we report that cAMP as well as MAPK activity and CREB phosphorylation are significantly higher in REM sleep compared with awake mice but not higher in NREM sleep. These increases do not occur in memory-deficient mice lacking calmodulinstimulated adenylyl cyclases. Our results support the hypothesis that the activation of the cAMP/MAPK/CREB transcriptional pathway during REM sleep contributes to memory consolidation and are consistent with electrophysiological studies showing replay activity in the hippocampus during REM sleep (Poe et al., 2000; Louie and Wilson, 2001).

\section{Materials and Methods}

Mice. Adult (3-6 months of age) male C57BL/6J wild-type (WT) and type 1 and type 8 adenylyl cyclases (AC1 and AC8) double-knock-out $(\mathrm{DKO})$ mice were used in the experiments. DKO mice were generated as previously described and backcross bred into C57BL/6J background for more than nine generations (Wong et al., 1999). Mice were entrained in a $12 \mathrm{~h}$ light/12 h dark cycle with lights on at 8:00 A.M. (ZT0) at least $7 \mathrm{~d}$ before the start of the experiment. Animal procedures were performed under protocols approved by the Institutional Animal Care and Use Committee of the University of Washington and conform to National Institutes of Health guidelines.

EEG implantations and recordings. Each mouse was implanted with an EEG headmount following the manufacturer's instructions (Pinnacle Technology). Briefly, mice were anesthetized with a ketamine/xylazine mixture and aligned in a stereotaxic apparatus. After exposing the skull surface, headmounts were centered along the sagittal suture with the front edge $3.5 \mathrm{~mm}$ anterior to bregma. Headmounts were then secured with four stainless steel screws (also functioned as EEG electrodes) and coated in acrylic for insulation. When positioned properly, all four screws (two anterior: AP $3.0 \mathrm{~mm}, \mathrm{ML} \pm 1.75 \mathrm{~mm}$; two posterior: $\mathrm{AP}-4.0$ $\mathrm{mm}, \mathrm{ML} \pm 1.75 \mathrm{~mm}$, relative to bregma) should sit on the cerebral region of an adult mouse (20-30 g). Two EMG wires were inserted bilaterally into the trapezius muscles to monitor neck activity. Mice were allowed $5 \mathrm{~d}$ to recover in their home cages before tethering to the commutators using $100 \times$ preamplifiers in circular recording cages. Mice were adapted to the recording apparatus for additional $5 \mathrm{~d}$ and EEG/EMG signals were collected using Sirenia software (Pinnacle Technology). Captured data were scored off-line manually to distinguish waking, REM sleep, and NREM sleep based on standard criteria including: (1) the amplitude and frequency of EEG; (2) the amplitude and frequency of EMG; and (3) the regularity of EEG/EMG. On the experimental day, mice were monitored based on both behavioral activities and EEG/EMG patterns. Mice were killed after 10 min in waking or NREM sleep or after 1 min in REM sleep between 12:00 P.M. (ZT4) and 2:00 P.M. (ZT6) to avoid variations resulted from circadian changes.

Passive avoidance. The training chamber was a shuttle box that was equally divided into lit and dark compartments by a metal partition with a trap door (Coulbourn Instruments). During training, mice were allowed to explore the lit side freely for $1 \mathrm{~min}$ before the trap door was opened. Immediately after mice entered the dark side, the door was closed and a mild foot shock $(0.7 \mathrm{~mA}, 2 \mathrm{~s})$ was delivered. Mice were kept in the dark side for $20 \mathrm{~s}$ and then returned to their home cages. During testing, mice were put back into the lit side, and the time mice spent before crossing over into the dark side (crossover latency) was recorded. The cutoff value for crossover latency was set to $5 \mathrm{~min}$.

Contextual fear conditioning. The contextual training and testing were performed in a contextual arena with clear sidewalls and a metal shock floor (Coulbourn Instruments). During training, mice were allowed to explore the chamber freely for $2 \mathrm{~min}$ before receiving a mild foot shock $(0.7 \mathrm{~mA}, 2 \mathrm{~s})$ from the metal grid. Mice were kept in the chamber for additional $1 \mathrm{~min}$ and returned to their home cages. During testing, mice were placed back into the training chamber without shock for $2 \mathrm{~min}$. Freezing behavior, defined by body immobility except for respiration, was scored every 10 s over a 2 min period. Data were presented as a percentage of time in freezing over total sampling period.

Immunohistochemistry. Mice were cervical dislocated and brains were removed quickly (within $2 \mathrm{~min}$ ) and immersed in $4 \%$ paraformalde- hyde/50 mm NaF/ $1 \mathrm{~mm} \mathrm{Na}_{3} \mathrm{VO}_{4}$ in $1 \times \mathrm{PBS}, \mathrm{pH} 7.4$, overnight at $4^{\circ} \mathrm{C}$, with one change of fixative after $3 \mathrm{~h}$. Brains were cryoprotected in $30 \%$ sucrose, frozen in 2-methylbutane/dry ice bath, and cut into serial coronal sections $(20 \mu \mathrm{m})$ in a cryostat (Leica). Sections were pretreated as previously described (Sindreu et al., 2007) and first stained with rabbit anti-phospho-p44/42 MAPK [also referred as extracellular signalregulated kinase 1 and 2 (ERK1/2), 1:10,000, Cell Signaling Technology]. The signal was amplified by deposition of cyanine- 3 tyramide complexes using Tyramide Signal Amplification System (PerkinElmer Life and Analytical Sciences). Sections were blocked again and incubated with rabbit anti-phospho-CREB (1:100, Cell Signaling Technology). Sections were then incubated with AlexaFluor-488-conjugated secondary antibody (Invitrogen), counterstained in DAPI (Invitrogen), and mounted using Aqua-Poly/Mount (Polysciences). Absence of cross-reactivity between the first primary antibody and the second secondary antibody was confirmed in experiments in which the second primary antibody was omitted (data not shown).

Imaging and analysis. Sections were imaged on either a Nikon Eclipse E400 Microscope or a Zeiss 510 Meta laser scanning confocal microscope. Density filter, pinhole, detector gain, and offset were kept constant for experimental comparisons. Hippocampal sections spanning between $-1.70 \mathrm{~mm}$ and $-2.18 \mathrm{~mm}$ relative to bregma were examined in the study. For phospho-ERK1/2 (pERK)-positive cells, four hippocampal sections per mouse were analyzed using $20 \times$ objective lens. Cell counts per subregion were averaged across sections and then across animals to yield group means. For phospho-CREB (pCREB) fluorescent intensity analysis, individual images were taken under $10 \times$ objective lens and montages were constructed and analyzed using Fiji software (National Institutes of Health). Area, mean gray value, and integrated intensity were measured and compared among three groups.

Western analysis. Mice were cervical dislocated, and hippocampi were quickly dissected out and homogenized with 50 strokes of Kontes "B" pestle in $200 \mu \mathrm{l}$ of lysis buffer [ $10 \mathrm{~mm}$ HEPES, pH 7.5, $150 \mathrm{~mm} \mathrm{NaCl}, 2.5$ mм EDTA, pH 8.0, 2.5 mм EGTA, pH 8.0, 50 mм NaF, 5 mм DTT, 1.5\% NP-40, 10\% glycerol, $1 \mathrm{~mm}$ PMSF, $1 \mathrm{~mm} \mathrm{Na} \mathrm{NO}_{4}, 1 \times$ phosphatase inhibitor mixture 2 and 3 (Sigma), and one tablet/10 Complete Mini EDTA-free protease inhibitor (Roche)]. Homogenates were spun at $14,000 \times g$ for $10 \mathrm{~min}$, and supernatant was retained as the whole-cell soluble fraction. Samples were mixed with equal amounts of Laemmli sample buffer (Bio-Rad), heated at $95^{\circ} \mathrm{C}$ for $10 \mathrm{~min}$, and loaded onto $4-15 \%$ Tris- $\mathrm{HCl}$ polyacrylamide gels (Bio-Rad) for SDS-PAGE analysis. Proteins were then transferred onto PVDF membranes (Millipore) and blocked with $5 \%$ BSA in $1 \times$ TBS with $0.05 \%$ Tween 20 . Blots were incubated with rabbit anti-phospho-(Ser/Thr) protein kinase A (PKA) substrates (referred as pPKA-s, 1:1000, Cell Signaling Technology) overnight at $4^{\circ} \mathrm{C}$. Blots were then incubated with alkaline phosphatase-conjugated secondary antibody (Sigma) and developed using CDP-Star substrate (Applied Biosystems). After stripping in $25 \mathrm{~mm}$ glycine/1\% SDS, $\mathrm{pH} 2.0$, for $40 \mathrm{~min}$ at room temperature, blots were blocked again and incubated with mouse anti-actin (1: 5000, Millipore). Protein bands were visualized with ChemiDoc XRS + system and analyzed using Image Lab software (Bio-Rad). Optical density of bands immunopositive for PPKA-s was normalized to that of corresponding actin bands.

Measurement of cAMP. Hippocampal homogenates were prepared as described above, except that $0.5 \mathrm{~mm}$ 3-isobutyl-1-methylxanthine was also included in the lysis buffer. Total cAMP activity was measured using Amersham cAMP Biotrak Enzymeimmunoassay System according to the manufacturer's instructions (GE Healthcare). The results were normalized by total protein amounts which were determined using Pierce BCA Protein Assay Kit (Thermo Scientific).

Statistical analysis. Results are expressed as mean \pm SEM. Behavioral data from passive avoidance and contextual fear conditioning studies were analyzed by two-way ANOVA. All other data were analyzed by one-way ANOVA. Bonferroni's multiple-comparison tests were followed for post hoc analysis. Significance was set at $p<0.05$. 


\section{Results}

Determination of mouse sleep architecture using EEG/EMG recordings

Prefabricated headmounts were implanted on top of the mouse skull to capture cortical EEG and neck EMG activities as described in Materials and Methods. Signals were then amplified, filtered, and transmitted to the recording units for documentation and analysis. Waking, REM sleep and NREM sleep were identified based on standard criteria as previously described (Tobler et al., 1997; Crocker and Sehgal, 2010). Waking was characterized by high-frequency, lowamplitude EEG signals in combination with chaotic EMG activity (Fig. 1A). REM sleep, however, exhibited regular and fast EEG spikes in low amplitude paralleled by the lack of EMG activity (Fig. $1 B$ ). NREM sleep was distinguished by low-frequency, high-amplitude EEG waves and attenuated muscle activity (Fig. 1C). Similar to adult humans (Carskadon and Dement, 2011), a cycle of waking-NREM sleepREM sleep was also detected in mice.

To examine the general sleep patterns of WT mice, we performed EEG/EMG recordings for five consecutive days. The data were then visually scored, and the percentages of time spent in total sleep, REM sleep, and NREM sleep were averaged across days and animals to yield group means. We observed that mice spent $44.3 \pm 0.5 \%$ of the recording time in total sleep over a $24 \mathrm{~h}$ period: $3.8 \pm 0.1 \%$ in REM sleep and $40.5 \pm 0.4 \%$ in NREM sleep (Fig. $2 A-C$ ). In the presence of light (ZT0-ZT12), mice spent $67.2 \pm 1.3 \%$ of the recording time in total sleep (Fig. $2 A$ ). The time spent in NREM sleep was $\sim 10$ times greater than that in REM sleep (NREM, $60.9 \pm 1.1 \%$; REM, $6.2 \pm 0.3 \%$; Fig. 2 B, C). In the absence of light (ZT12-ZT24), mice spent much less time in sleep $(21.4 \pm 1.3 \%$; Fig. $2 A)$. However, the time in NREM sleep increased to 15 times as many as that in REM sleep (NREM, $20.1 \pm 1.3 \%$; REM, $1.3 \pm 0.2 \%$; Fig. $2 B, C$ ). When further analyzed in $4 \mathrm{~h}$ intervals, we detected parallel oscillations of time spent in total sleep, REM sleep, and NREM sleep over a $24 \mathrm{~h}$ period (Fig. 2D-F). The preponderance of sleep during the light phase corresponds to normal sleep patterns of mice under 12:12 light/dark entrained conditions (Veasey et al., 2000).

\section{Activation of MAPK and CREB during REM sleep}

We previously discovered that MAPK activity and CREB phosphorylation underwent circadian oscillations with peak activities between ZT4 and ZT8 (Eckel-Mahan et al., 2008). In the present study, we hypothesized that the molecular components involved in memory consolidation may be reactivated during specific phases of sleep within this period. Therefore, experiments were performed between ZT4 and ZT6 to monitor changes in MAPK activity during waking and sleep. The behavioral states of mice were identified based on their physical activities and EEG/EMG signals. Awake mice demonstrated full awareness to the environment and high levels of EMG activity. Mice in sleep lay motion- less with closed eyes and sometimes with head tucked under the body. Because NREM sleep usually stays long $(19.7 \pm 1.3 \mathrm{~min})$ whereas REM sleep is transitory $(3.1 \pm 0.1 \mathrm{~min})$, mice were allowed $10 \mathrm{~min}$ in waking or NREM sleep but $1 \mathrm{~min}$ in REM sleep before cervical dislocation. MAPK activity was determined by immunostaining hippocampal sections for dually phosphorylated, activated MAPK (pERK) (Atkins et al., 1998; Sindreu et al., 2007), and cells immunopositive for pERK were counted in the pyramidal layer of the CA1 and the granular layer of the dentate gyrus (DG). We detected pERK labeling in both cell bodies and apical dendrites (Fig. $3 A$ ). In the CA1, there were 3 times more $\mathrm{pERK}^{+}$cells in mice during REM sleep compared with awake mice $\left(\mathrm{REM}, 73 \pm 5\right.$; waking, $23 \pm 5$; one-way ANOVA, $F_{(2,16)}=$ $41.05, p<0.0001 ;$ Fig. $3 B)$. No significant difference was detected between NREM sleep and waking (NREM, $16 \pm 5$; waking, $23 \pm$ 5; Fig. $3 B$ ). In the DG, a significant increase in $\mathrm{pERK}^{+}$cells, although to a lesser extent, was also detected in mice during REM sleep compared with awake mice (REM, $9 \pm 1$; waking, $5 \pm 1$; one-way ANOVA, $F_{(2,16)}=8.944, p=0.0025$; Fig. $3 C$ ). Moreover, the numbers of $\mathrm{pERK}^{+}$cells in mice during REM sleep were higher than those during NREM sleep in the CA1 $(p<0.001)$ and DG $(p<0.01)$.

MAPK activation of CREB-mediated transcription is strongly implicated in memory consolidation and is activated during training for hippocampus-dependent memory (Bourtchuladze et al., 1994; Wu et al., 1995; Atkins et al., 1998; Impey et al., 1998b; Wong et al., 1999; Athos et al., 2002; Pittenger et al., 2002; Sindreu et al., 2007). To examine changes in CREB activity be- 
A

Total Sleep Time

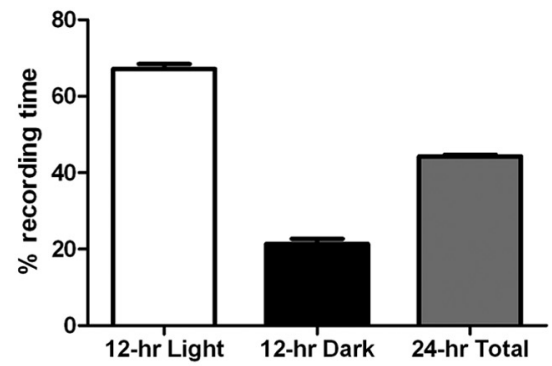

D

Total Sleep Time

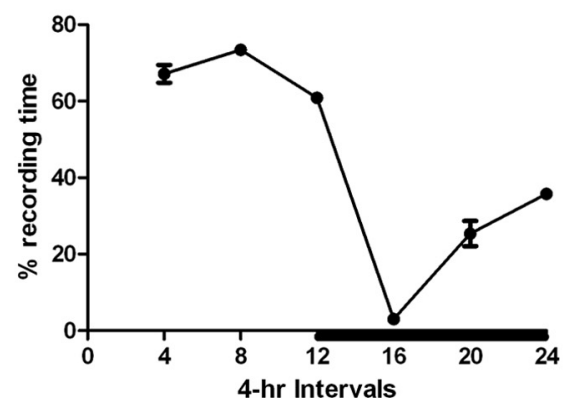

B

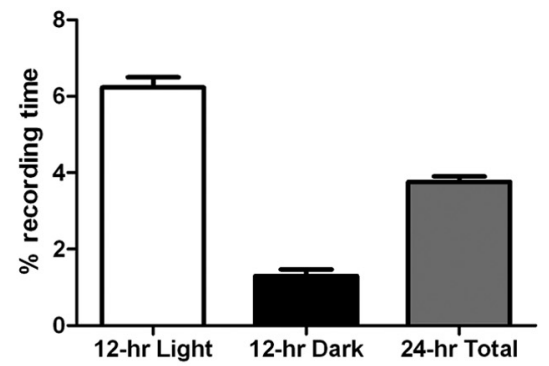

E

REM

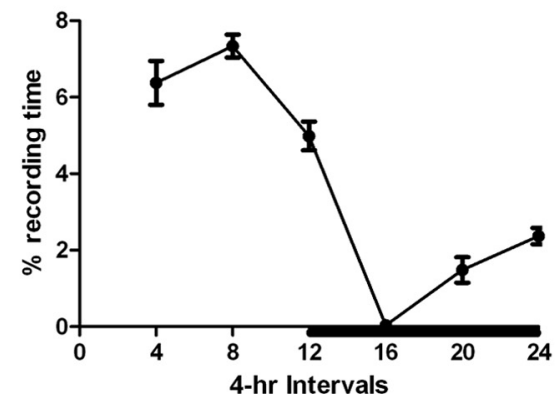

C

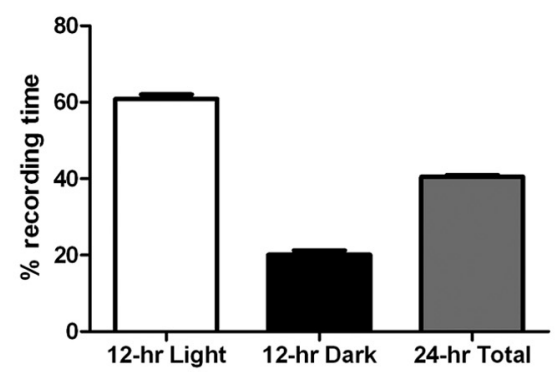

$\mathbf{F}$

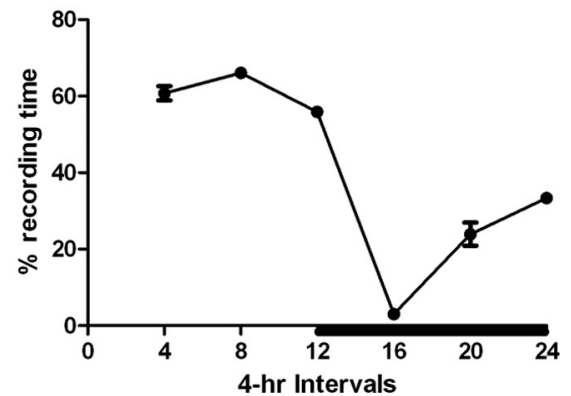

Figure 2. Sleep architecture of WT mice under entrained ( $12 \mathrm{~h}$ light/ $12 \mathrm{~h}$ dark) conditions. $A-C$, Percentages of time spent in total sleep, REM sleep, and NREM sleep were averaged ( $n=5$, for 5 consecutive days, mean \pm SEM) over $12 \mathrm{~h}$ light, $12 \mathrm{~h}$ dark and total $24 \mathrm{~h}$ recording period. $\boldsymbol{D}-\boldsymbol{F}$, Percentages of time in total sleep, REM sleep, and NREM sleep were averaged ( $n=5$, for 5 consecutive days, mean \pm SEM) in $4 \mathrm{~h}$ intervals. The dark phase is indicated on the $x$-axis. ZTO, lights on at 8:00 A.M.

A
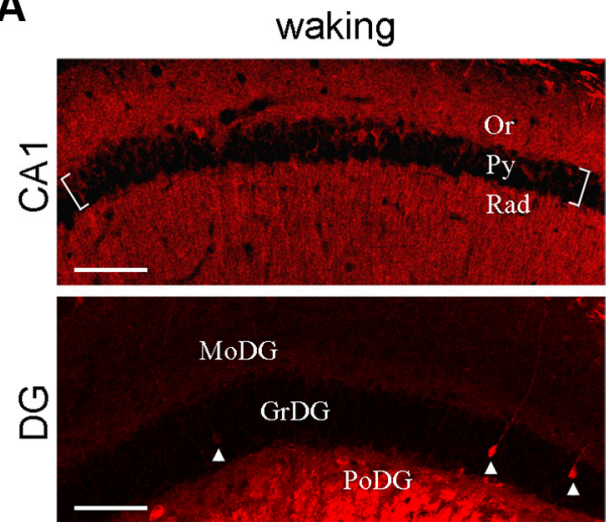

B

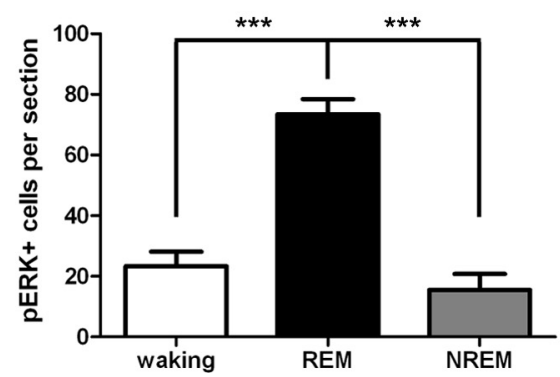

REM
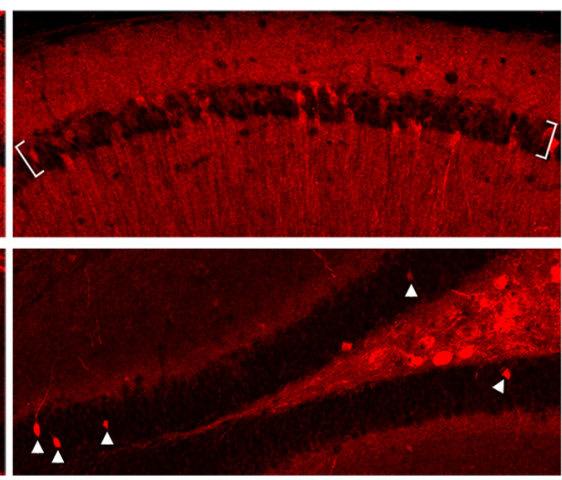

C

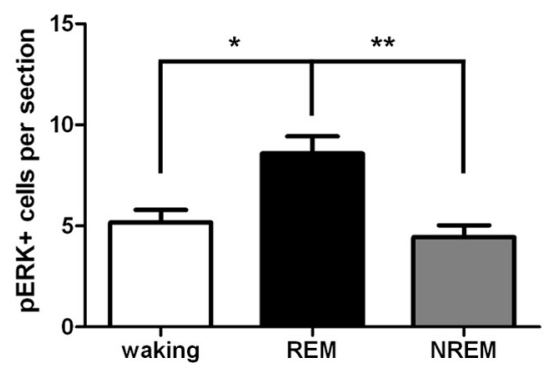

Figure 3. Increased numbers of pERK-immunopositive cells in the CA1 and DG during REM sleep. $A$, Confocal images of pERK ${ }^{+}$cells in the CA1 (outlined with brackets) and DG from mice during waking, REM sleep, and NREM sleep. Arrowheads indicate pERK ${ }^{+}$cells in the DG. Scale bar, $100 \mu \mathrm{m}$. Or, Oriens layer; Py, pyramidal layer; Rad, radiatum layer; MoDG, molecular dentate gyrus; GrDG, granular dentate gyrus; PoDG, polymorph dentate gyrus. $\boldsymbol{B}, \boldsymbol{C}$, Quantification of the numbers of $\mathrm{pERK}{ }^{+}$cells per section in the pyramidal layer of the $C A 1(\boldsymbol{B})$ and the granular layer of the DG $(\boldsymbol{C})$. Data are mean \pm SEM; $n=5-8$ per group. ${ }^{*} p<0.05$ (one-way ANOVA, Bonferroni's post hoc). ${ }^{* *} p<0.01$ (one-way ANOVA, Bonferroni's post hoc). ${ }^{* * *} p<0.001$ (one-way ANOVA, Bonferroni's posthoc). 


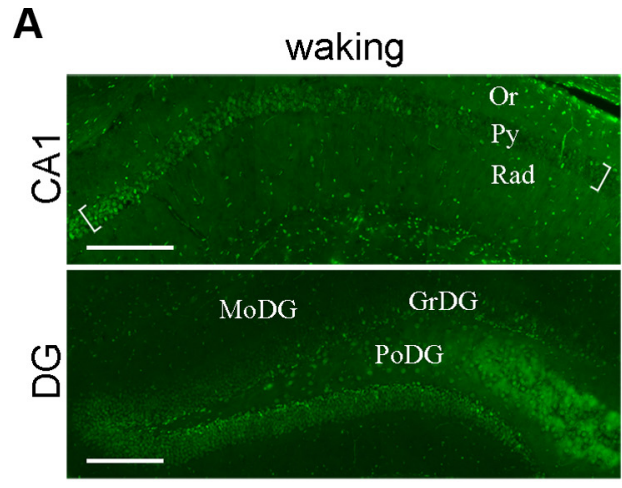

B

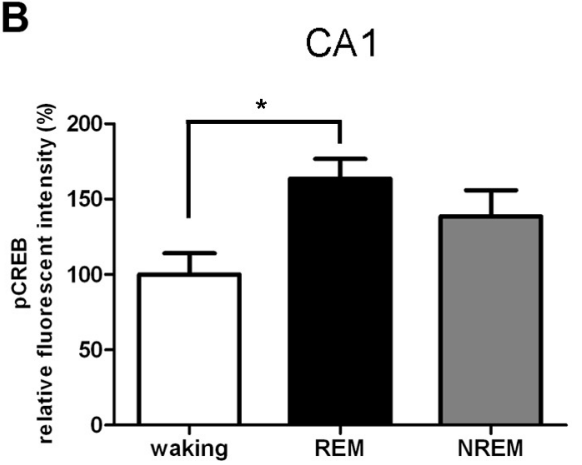

REM
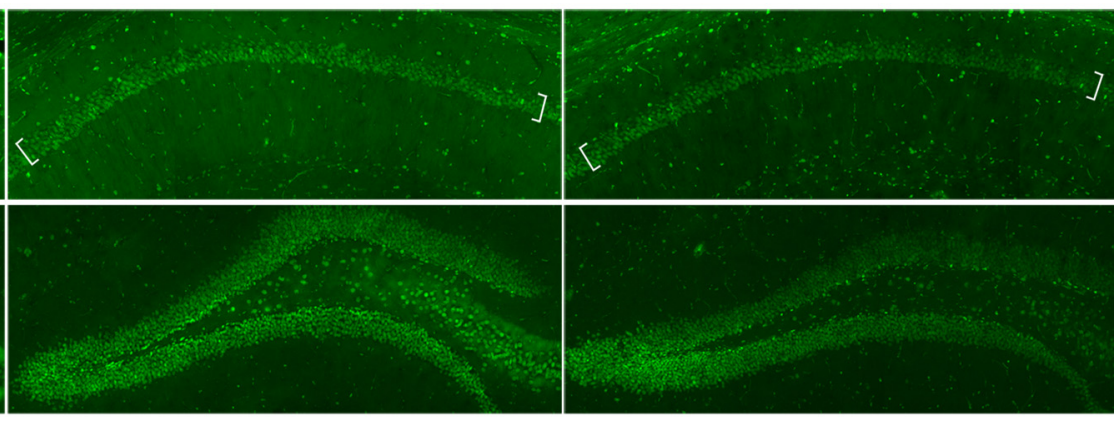

C

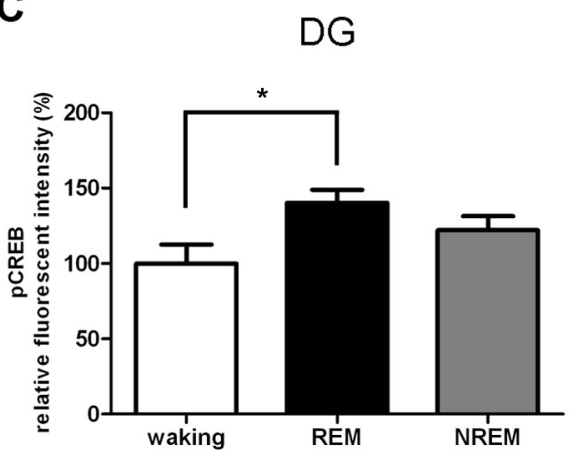

Figure 4. Elevated pCREB immunoreactivity in the CA1 and DG during REM sleep. $\boldsymbol{A}$, Immunofluorescent images of pCREB in the CA1 (outlined with brackets) and DG from mice during waking, REM sleep, and NREM sleep. Scale bar, $200 \mu \mathrm{m}$. Or, Oriens layer; Py, pyramidal layer; Rad, radiatum layer; MoDG, molecular dentate gyrus; GrDG, granular dentate gyrus; PoDG, polymorph dentate gyrus. $\boldsymbol{B}, \boldsymbol{C}$, Quantification of the relative fluorescent intensity of $\mathrm{pCREB}$ in the pyramidal layer of the $\left(\mathrm{A} 1(\boldsymbol{B})\right.$ and the granular layer of the $D G(\boldsymbol{C})$. Data are mean \pm SEM; $n=5-8$ per group. ${ }^{*} p<$ 0.05 (one-way ANOVA, Bonferroni's post hoc).

tween waking and sleep, we immunostained hippocampal sections for CREB phosphorylated at Ser-133 (pCREB). Because we observed a large number of cells immunopositive for pCREB in the CA1 and DG (Fig. 4A), we compared total fluorescent intensity within the subregions among three behavioral states. The intensity of pCREB immunofluorescence was significantly higher in REM sleep compared with awake mice in the CA1 (one-way ANOVA, $F_{(2,16)}=5.117, p=0.0191$; Fig. $4 B$ ) and DG (one-way ANOVA, $F_{(2,16)}=4.109, p=0.0363$; Fig. $4 C$ ), but not in NREM sleep relative to awake animals. Together, these data indicate that MAPK activity and CREB phosphorylation increase during REM sleep in the CA1 pyramidal layer and DG granular layer of the hippocampus compared with awake mice.

\section{Hippocampal cAMP/PKA signaling increases during REM sleep}

cAMP is required for activation and nuclear translocation of MAPK as well as subsequent CREB phosphorylation during memory formation (Impey et al., 1998b; Sindreu et al., 2007). We therefore measured cAMP levels and PKA activity between waking and sleep. The average hippocampal cAMP of all mice examined (including waking, REM, and NREM groups) between ZT4 and ZT6 was $30.9 \pm 2.7 \mathrm{pmol} / \mathrm{mg}$ of protein. Within this time frame, however, the cAMP level was greatest in REM sleep $(41.0 \pm 4.1 \mathrm{pmol} / \mathrm{mg}$ of protein), significantly higher than that in awake animals or NREM sleep (one-way ANOVA, $F_{(2,14)}=$ 6.155, $p=0.0121$; Fig. 5A).

To generally monitor cAMP-dependent PKA activity during sleep, we examined the levels of downstream substrates phosphorylated by PKA using Western analysis. An antibody that detects proteins phosphorylated at a conserved PKA phosphorylation motif was used, and the immunoreactivity was determined by the optical intensity of the bands. Of an array of bands detected, we analyzed three (labeled 1-3) in sizes ranging between 50 and $100 \mathrm{kDa}$ for PKA activity during waking and sleep (Fig. $5 B)$. An increase in pPKA-s labeling during REM sleep compared with awake animals was detected in all three bands analyzed, two of which were significantly higher (band 2, one-way ANOVA, $F_{(2,14)}=11.62, p=0.0011$; band 3, one-way ANOVA, $F_{(2,14)}=$ $15.68, p=0.0003$; Fig. $5 C$ ). It was also evident that pPKA-s intensity was greatly enhanced during REM sleep relative to NREM sleep (band 1, $p<0.01$; band 2, $p<0.01$; band 3, $p<0.001$ ). However, PKA activity between NREM sleep and waking was not statistically different. In addition, although the specific PKA substrates showing higher phosphorylation during REM sleep were not characterized here, CREB phosphorylation was significantly higher during REM sleep (Fig. 4). Collectively, these data indicate that hippocampal cAMP/PKA signaling is higher during REM sleep than in animals that are awake.

\section{Calmodulin-stimulated adenylyl cyclases are required for memory consolidation and activation of the cAMP/MAPK/ CREB transcriptional pathway during REM sleep}

We reasoned that the increase in the cAMP/MAPK/CREB signaling cascade during REM sleep might contribute to memory consolidation. However, because REM sleep in mice is very brief $(3.1 \pm 0.1 \mathrm{~min})$ and occurs at a low frequency $(3.8 \pm 0.1 \%$ of total recording time), it is impossible to block the pathway exclusively during REM sleep using chemical inhibitors. Instead, we chose a transgenic mouse model showing deficits in memory consolidation and examined the activation of the cAMP/MAPK/CREB pathway during sleep. DKO mice have impairments in long-term potentiation (LTP) at the Schaffer collateral-CA1 synapses (Wong et al., 1999; Zhang et al., 2011), as well as in long-term 
A

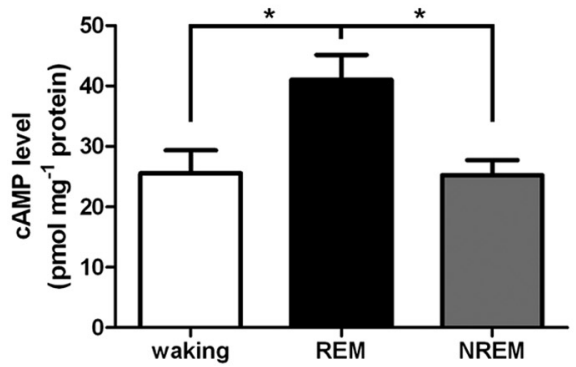

B

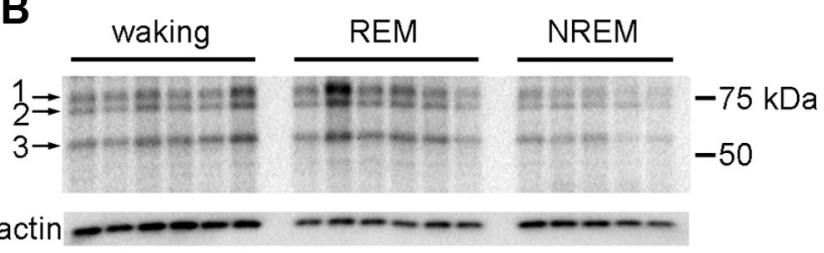

C

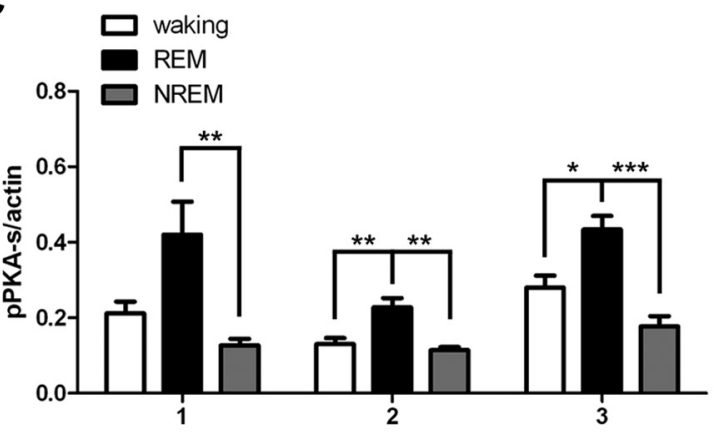

Figure 5. CAMP/PKA signaling increases during REM sleep. $A$, cAMP levels of hippocampi taken from mice during waking, REM sleep, and NREM sleep. Data are mean \pm SEM; $n=5$ or 6 per group. ${ }^{*} p<0.05$ (one-way ANOVA, Bonferroni's post hoc). $\boldsymbol{B}$, Images of immunoblots probed with pPKA-s and actin. Blots show individually run samples. pPKA-s bands labeled 1-3 were analyzed. The ladder is indicated on the right. $C$, Summary of the relative levels of three pPKA-s bands (1-3). Data are mean \pm SEM; $n=5$ or 6 per group. ${ }^{*} p<0.05$ (one-way ANOVA, Bonferroni's post hoc). ${ }^{* *} p<0.01$ (one-way ANOVA, Bonferroni's post hoc). ${ }^{* *} p<0.001$ (one-way ANOVA, Bonferroni's post hoc).

memory for several hippocampus-dependent tasks (Wong et al., 1999; Wang et al., 2004; Zhang et al., 2011). When subjected to passive avoidance test, both WT and DKO mice exhibited increased crossover latency at comparable levels $3 \mathrm{~h}$ after training (two-way ANOVA, genotype, $F_{(1,24)}=1.37, p=0.2537$; trial, $F_{(1,24)}=49.36, p<0.0001$; interaction, $F_{(1,24)}=2.04, p=0.1660$; Fig. $6 A$ ), suggesting that DKO mice have normal learning and short-term memory for passive avoidance task. However, when tested for long-term passive avoidance memory, DKO mice showed significantly shorter crossover latency compared with WT mice $24 \mathrm{~h}$ after training (two-way ANOVA, genotype, $F_{(1,32)}=$ 25.47, $p<0.0001$; trial, $F_{(1,32)}=64.82, p<0.0001$; interaction, $F_{(1,32)}=25.98, p<0.0001$; Fig. $\left.6 B\right)$. In another test where memory for contextual fear was evaluated, DKO mice learned to associate the contextual chamber with aversive foot shock and demonstrated elevated freezing behavior similar to that of WT mice $3 \mathrm{~h}$ after training (two-way ANOVA, genotype, $F_{(1,24)}=$ $0.48, p=0.4956$; trial, $F_{(1,24)}=70.89, p<0.0001$; interaction, $F_{(1,24)}=0.21, p=0.6486$; Fig. $\left.6 C\right)$. However, DKO mice spent significantly less time in freezing than WT mice $24 \mathrm{~h}$ and $8 \mathrm{~d}$ after training (two-way ANOVA, genotype, $F_{(1,21)}=51.77, p<0.0001$; trial, $F_{(2,21)}=30.15, p<0.0001$; interaction, $F_{(2,21)}=14.42, p=$ 0.0001 ; Fig. $6 D$ ). These results indicate that consolidation of hippocampus-dependent memory is compromised in DKO mice and that calmodulin-stimulated adenylyl cyclases are indispensable for memory consolidation.

MAPK activity, CREB phosphorylation, and cAMP/PKA signaling during sleep and awake periods were analyzed in DKO mice. Quantification of $\mathrm{pERK}^{+}$cells revealed no significant differences among waking, REM sleep, and NREM sleep in the pyramidal layer of the CA1 (one-way ANOVA, $F_{(2,17)}=3.476$, $p=0.0543$; Fig. $7 A$ ). In addition, the total fluorescent intensity of pCREB in the CA1 remained relatively constant among three behavioral states (one-way ANOVA, $F_{(2,17)}=1.119, p=0.3495$; Fig. $7 B$ ), suggesting that REM sleep-associated CREB activation was abolished in DKO mice. We also monitored cAMP levels and PKA activity in the hippocampus of DKO mice. No differences in cAMP levels (Fig. 7C) or PKA activity (Fig. 7D,E) were detected between waking and REM sleep. However, in DKO mice, cAMP and PKA activity was higher in NREM sleep compared with awake mice (cAMP, one-way ANOVA, $F_{(2,18)}=4.659, p=$ 0.0234 ; band 1, one-way ANOVA, $F_{(2,18)}=6.950, p=0.0058$; band 2, one-way ANOVA, $F_{(2,18)}=10.38, p=0.0010$; band 3, one-way ANOVA, $F_{(2,18)}=18.98, p<0.0001$; Fig. $\left.7 C-E\right)$. We do not know why there is an increase in cAMP during NREM sleep in DKO mice. However, there are at least 7 different adenylyl cyclases expressed in the hippocampus with different regulatory properties (Hanoune and Defer, 2001). The fact that one can see a differential increase in cAMP during REM sleep but not NREM sleep in WT mice clearly indicates that there are different mechanisms for activation of adenylyl cyclases in REM and NREM sleep. The higher levels of cAMP and PKA activity during NREM sleep may result from compensation because of the loss of calmodulin-stimulated adenylyl cyclases. Nevertheless, the increases in pERK, pCREB, and cAMP/PKA during REM sleep relative to awake animals observed in WT mice are lost in DKO mice, a memory-deficient mouse strain. Collectively, our data suggest that calmodulin-stimulated adenylyl cyclases are required for activation of the cAMP/MAPK/CREB pathway during REM sleep and that the preferential activation of this pathway during REM sleep may contribute to memory consolidation.

\section{Discussion}

The cAMP, MAPK, and CREB-mediated transcription is activated during the formation of hippocampus-dependent longterm memory (Atkins et al., 1998; Blum et al., 1999; Wong et al., 1999; Pittenger et al., 2002; Sindreu et al., 2007), an event that requires de novo transcription and translation (Davis and Squire, 1984; Silva et al., 1998; Impey et al., 1999). However, traininginduced increases in cAMP, MAPK activity, and CREB phosphorylation are transient (Bernabeu et al., 1997; Sindreu et al., 2007), and the newly synthesized synaptic proteins have limited lifetimes. Therefore, it is not clear how hippocampus-dependent memories are maintained over extended periods of time. We recently discovered that the $\mathrm{CAMP/MAPK/CREB} \mathrm{transcriptional}$ pathway in the mouse hippocampus is repeatedly activated during the circadian cycle with a maximum during the daytime (Eckel-Mahan et al., 2008) that depends upon the suprachiasmatic nucleus (SCN) (Phan et al., 2011). Disruption of this oscillation after acquisition and consolidation impairs the persistence of memory. Because mice are nocturnal and exhibit polyphasic sleep patterns during the daytime, it raised the interesting possibility that this memory consolidation pathway may be activated during sleep. The objective of this study was to monitor the cAMP/MAPK/CREB transcriptional pathway during various stages of sleep. 
In this study, we took advantage of the EEG/EMG recording system and monitored cAMP, MAPK activity, and CREB phosphorylation in the hippocampus of mice during REM sleep, NREM sleep, and when mice were awake. MAPK activation, measured as pERK, has been implicated in consolidation of hippocampus-dependent memory (Kelly et al., 2003; Kelleher et al., 2004). When comparing MAPK activity among waking, REM sleep, and NREM sleep, we detected much higher pERK levels in the CA1 and DG during REM sleep compared with waking but not when comparing NREM sleep with waking. We also examined the levels of phospho-p38 MAPK, which oscillates out of phase relative to pERK in the SCN (Obrietan et al., 1998; Pizzio et al., 2003), in sleeping and awake animals. However, no differences were detected among different behavioral states (data not shown).

Because MAPK mediates phosphorylation and transactivation of CREB during memory formation (Xing et al., 1996; Impey et al., 1998b; Sindreu et al., 2007), and more importantly, CREBmediated transcription is required for consolidation of hippocampus-dependent memory (Bourtchuladze et al., 1994; Athos et al., 2002; Pittenger et al., 2002), we examined CREB phosphorylation in REM and
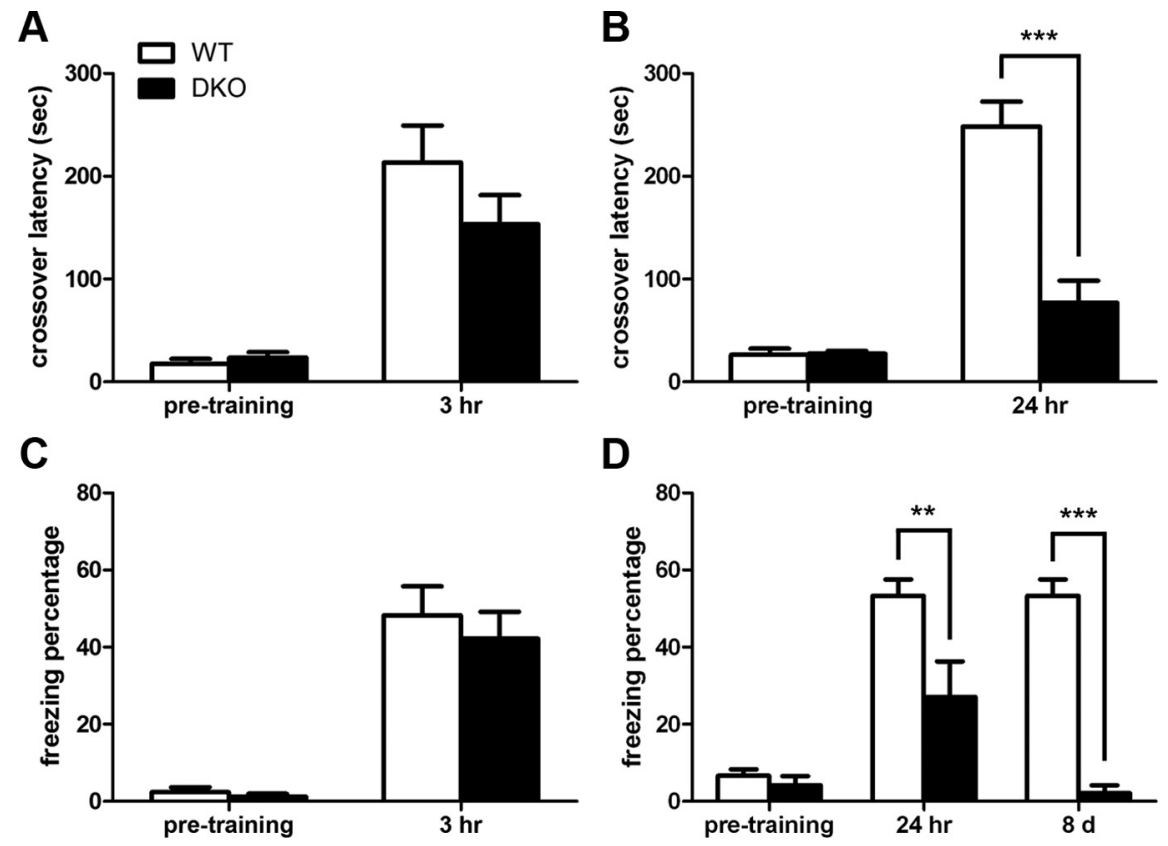

Figure 6. DKO mice exhibit impairments in consolidating hippocampus-dependent memory. $\boldsymbol{A}$, WT (open bars) and DKO (closed bars) mice were trained in the passive avoidance test, and crossover latency was measured $3 \mathrm{~h}$ after training. Data are mean \pm SEM; $n=7$ per group. $\boldsymbol{B}$, WT and DKO mice were tested for passive avoidance memory $24 \mathrm{~h}$ after training. Data are mean \pm SEM; $n=8-10$ per group. ${ }^{* * *} p<0.001$ (two-way ANOVA, Bonferroni's post hoc). C, WT and DKO mice were trained for contextual learning, and freezing percentage was measured $3 \mathrm{~h}$ after training. Data are mean $\pm S E M ; n=7$ per group. $D$, WT and DKO mice were tested for contextual fear memory $24 \mathrm{~h}$ and $8 \mathrm{~d}$ after training. Data are mean \pm SEM; $n=4$ or 5 per group. ${ }^{* *} p<$ 0.01 (two-way ANOVA, Bonferroni's post hoc). ${ }^{* * *} p<0.001$ (two-way ANOVA, Bonferroni's post hoc).
A

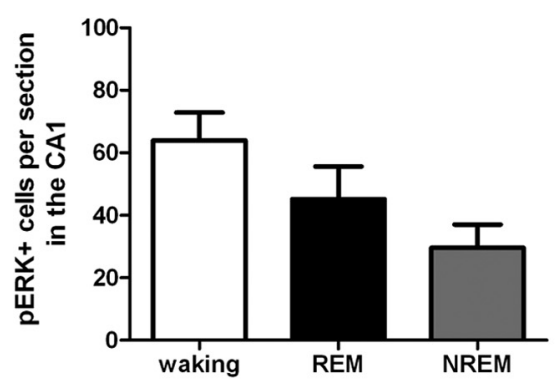

D

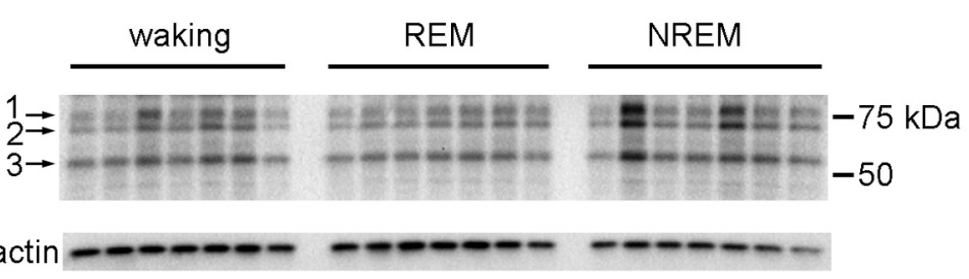

B

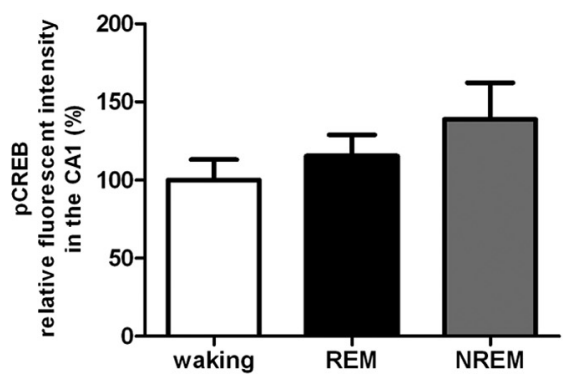

C

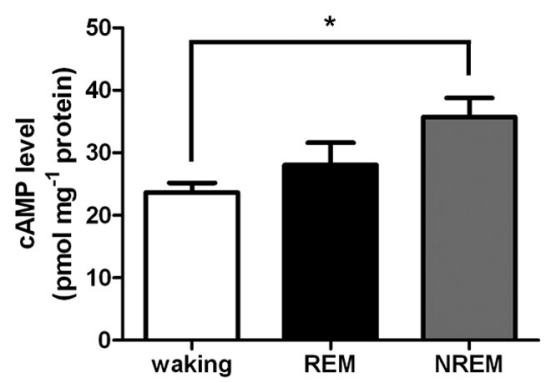

E

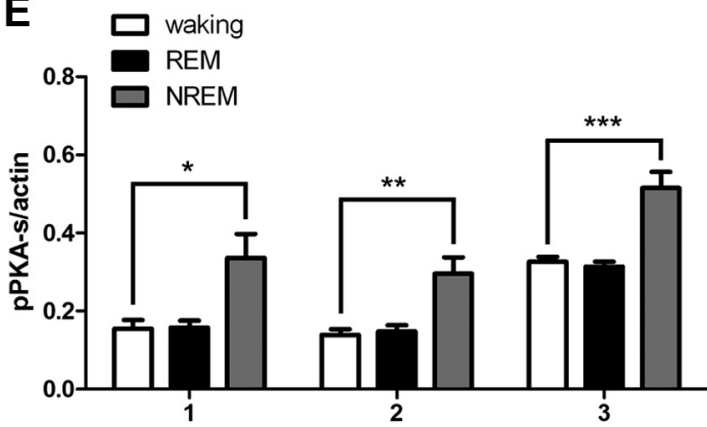

Figure 7. The cAMP/MAPK/CREB activation is attenuated during REM sleep in DKO mice. $A$, Quantification of the numbers of $p E R K{ }^{+}$cells per section in the CA1 of DKO mice during waking, REM sleep, and NREM sleep. Data are mean \pm SEM; $n=6$ or 7 per group. $B$, Analysis of the relative fluorescent intensity of pCREB in the CA 1 of DKO mice in three behavioral states. Data are mean \pm SEM; $n=6-8$ per group. C, Hippocampal cAMP from DKO mice in waking, REM sleep, and NREM sleep. Data are mean \pm SEM; $n=7$ per group. ${ }^{*} p<0.05$ (one-way ANOVA, Bonferroni's post hoc). $D$, Images of immunoblots probed with pPKA-s and actin. Blots show individually run samples. pPKA-s bands labeled $1-3$ were analyzed. The ladder is indicated on the right. $E$, Summary of the relative levels of three pPKA-s bands (1-3). Data are mean \pm SEM; $n=7$ per group. ${ }^{*} p<0.05$ (one-way ANOVA, Bonferroni's post hoc). ${ }^{* *} p<0.01$ (one-way ANOVA, Bonferroni's post hoc). $* * * p<0.001$ (one-way ANOVA, Bonferroni's post hoc). 
NREM sleep. We used a phosphopeptide-specific antibody for CREB phosphorylated at Ser-133 (Impey et al., 1998a) and discovered that pCREB levels were significantly higher in REM sleep compared with waking but not when comparing NREM sleep with waking.

MAPK is activated by cAMP in the hippocampus (Impey et al., 1998b; Roberson et al., 1999). We next examined cAMP levels and discovered that cAMP was also higher during REM sleep compared with awake animals. In addition, to assess cAMPdependent PKA activity between waking and sleep, we used an antibody that detects the downstream substrates sharing a conserved PKA phosphorylation motif as a general indicator for PKA activation (Sindreu et al., 2007). We detected elevated levels of two PKA substrates ranging from 50 to $75 \mathrm{kDa}$ during REM sleep. One potential candidate of these substrates is STEP ${ }_{61}$, the only isoform of the striatal-enriched protein tyrosine phosphatase (STEP) family that is expressed in the hippocampus (Boulanger et al., 1995). STEP is phosphorylated directly by PKA (Paul et al., 2000). In addition, the activity of STEP is also regulated by PKAactivated DARPP-32 (dopamine and cyclic adenosine $3^{\prime}, 5^{\prime}$ monophosphate-regulated phosphoprotein, $32 \mathrm{kDa}$ ), which blocks the inhibitory activity of protein phosphatase- 1 and therefore retains STEP in phosphorylated state (Greengard et al., 1999; Fitzpatrick and Lombroso, 2011). The resulting phosphorylation of STEP prevents it from interacting with and inactivating pERK by dephosphorylation at the regulatory tyrosine residue (Paul et al., 2003). To evaluate the levels of phospho-STEP ${ }_{61}$ during waking and sleep, we processed hippocampal lysates for Western analysis and observed an increase in phospho-STEP ${ }_{61}$ during REM sleep compared with waking or NREM sleep. However, these differences were not statistically significant (data not shown). Nevertheless, our data have shown that CREB, an important downstream target of the cAMP/PKA pathway, is activated during REM sleep (Fig. 4). Together, our results indicate that cAMP, MAPK activity, and CREB phosphorylation are significantly higher in REM sleep, but not in NREM sleep, compared with awake mice.

The fact that the cAMP/MAPK/CREB transcriptional pathway is elevated during REM sleep suggests the intriguing hypothesis that the activation of this pathway during REM sleep may contribute to memory consolidation. To test this hypothesis, one has to demonstrate that blocking the activation of this pathway during REM sleep compromises memory consolidation. However, it is impossible to disrupt this pathway specifically during the brief periods of REM sleep with chemical inhibitors. We therefore used DKO transgenic mice as a tool to block calmodulin-stimulated cAMP increases during REM sleep. There is no difference between the sleep architecture of DKO and WT mice (J.L. and D.R.S., unpublished observations). However, DKO mice exhibit impairments in consolidating hippocampusdependent memory and no increases in cAMP, MAPK activity, or CREB phosphorylation during REM sleep. These data support the hypothesis that memory consolidation depends upon cAMP signals generated by calmodulin-stimulated adenylyl cyclases during REM sleep that activate MAPK and CREBmediated transcription.

There is considerable evidence supporting the idea that memory consolidation may occur during REM sleep in rodents. Training leads to an increase in subsequent REM sleep, the onset time and duration of which vary depending upon task complexity, animal species, and training protocols (Smith, 1996; Peigneux et al., 2001; Rauchs et al., 2005). In addition, depriving REM sleep after training interferes with spatial reference memory in maze learning (Smith and Rose, 1996; Youngblood et al., 1997; Smith et al., 1998). Furthermore, neuronal activities reflecting prior waking experience are reproduced in a temporal order during subsequent REM sleep (Poe et al., 2000; Louie and Wilson, 2001). However, hippocampal ensemble discharges seen in the earlier learning episodes are also detected during SWS (Wilson and McNaughton, 1994; Skaggs and McNaughton, 1996; Shen et al., 1998; Ji and Wilson, 2007). These results suggest that REM sleep and SWS may play complementary roles in consolidating memory obtained from preceding wakefulness. In conclusion, our data indicate that the activation of the cAMP/MAPK/CREB transcriptional pathway during REM sleep may play an important role in consolidation of hippocampus-dependent memory.

\section{References}

Allada R, Siegel JM (2008) Unearthing the phylogenetic roots of sleep. Curr Biol 18:R670-R679. CrossRef Medline

Aserinsky E, Kleitman N (1953) Regularly occurring periods of eye motility, and concomitant phenomena, during sleep. Science 118:273-274. CrossRef Medline

Athos J, Impey S, Pineda VV, Chen X, Storm DR (2002) Hippocampal CREmediated gene expression is required for contextual memory formation. Nat Neurosci 5:1119-1120. CrossRef Medline

Atkins CM, Selcher JC, Petraitis JJ, Trzaskos JM, Sweatt JD (1998) The MAPK cascade is required for mammalian associative learning. Nat Neurosci 1:602-609. CrossRef Medline

Bernabeu R, Cammarota M, Izquierdo I, Medina JH (1997) Involvement of hippocampal AMPA glutamate receptor changes and the cAMP/protein kinase A/CREB-P signalling pathway in memory consolidation of an avoidance task in rats. Braz J Med Biol Res 30:961-965. CrossRef Medline

Blum S, Moore AN, Adams F, Dash PK (1999) A mitogen-activated protein kinase cascade in the CA1/CA2 subfield of the dorsal hippocampus is essential for long-term spatial memory. J Neurosci 19:3535-3544. Medline

Boulanger LM, Lombroso PJ, Raghunathan A, During MJ, Wahle P, Naegele JR (1995) Cellular and molecular characterization of a brain-enriched protein tyrosine phosphatase. J Neurosci 15:1532-1544. Medline

Bourtchuladze R, Frenguelli B, Blendy J, Cioffi D, Schutz G, Silva AJ (1994) Deficient long-term memory in mice with a targeted mutation of the cAMP-responsive element-binding protein. Cell 79:59-68. CrossRef Medline

Campbell SS, Tobler I (1984) Animal sleep: a review of sleep duration across phylogeny. Neurosci Biobehav Rev 8:269-300. CrossRef Medline

Carskadon MA, Dement WC (2011) Monitoring and staging human sleep. In: Principles and practice of sleep medicine, Ed 5 (Kryger TR, Dement WC, eds), pp 16-26. St. Louis: Elsevier Saunders.

Cirelli C, Tononi G (2008) Is sleep essential? PLoS Biol 6:e216. CrossRef Medline

Crocker A, Sehgal A (2010) Genetic analysis of sleep. Genes Dev 24:12201235. CrossRef Medline

Davis HP, Squire LR (1984) Protein synthesis and memory: a review. Psychol Bull 96:518-559. CrossRef Medline

Diekelmann S, Born J (2010) The memory function of sleep. Nat Rev Neurosci 11:114-126. CrossRef Medline

Eckel-Mahan KL, Phan T, Han S, Wang H, Chan GC, Scheiner ZS, Storm DR (2008) Circadian oscillation of hippocampal MAPK activity and cAMP: implications for memory persistence. Nat Neurosci 11:1074-1082. CrossRef Medline

Fitzpatrick CJ, Lombroso PJ (2011) The role of striatal-enriched protein tyrosine phosphatase (STEP) in cognition. Front Neuroanat 5:47. CrossRef Medline

Greengard P, Allen PB, Nairn AC (1999) Beyond the dopamine receptor: the DARPP-32/protein phosphatase-1 cascade. Neuron 23:435-447. CrossRef Medline

Hanoune J, Defer N (2001) Regulation and role of adenylyl cyclase isoforms. Annu Rev Pharmacol Toxicol 41:145-174. CrossRef Medline

Hernandez PJ, Abel T (2011) A molecular basis for interactions between sleep and memory. Sleep Med Clin 6:71-84. CrossRef Medline

Impey S, Smith DM, Obrietan K, Donahue R, Wade C, Storm DR (1998a) Stimulation of cAMP response element (CRE)-mediated transcription during contextual learning. Nat Neurosci 1:595-601. CrossRef Medline 
Impey S, Obrietan K, Wong ST, Poser S, Yano S, Wayman G, Deloulme JC, Chan G, Storm DR (1998b) Cross talk between ERK and PKA is required for $\mathrm{Ca}^{2+}$ stimulation of CREB-dependent transcription and ERK nuclear translocation. Neuron 21:869-883. CrossRef Medline

Impey S, Obrietan K, Storm DR (1999) Making new connections: role of ERK/MAP kinase signaling in neuronal plasticity. Neuron 23:11-14. CrossRef Medline

Ji D, Wilson MA (2007) Coordinated memory replay in the visual cortex and hippocampus during sleep. Nat Neurosci 10:100-107. CrossRef Medline

Kelleher RJ 3rd, Govindarajan A, Jung HY, Kang H, Tonegawa S (2004) Translational control by MAPK signaling in long-term synaptic plasticity and memory. Cell 116:467-479. CrossRef Medline

Kelly A, Laroche S, Davis S (2003) Activation of mitogen-activated protein kinase/extracellular signal-regulated kinase in hippocampal circuitry is required for consolidation and reconsolidation of recognition memory. J Neurosci 23:5354-5360. Medline

Lesku JA, Rattenborg NC, Amlaner CJ Jr (2006) The evolution of sleep: a phylogenetic approach. In: Sleep: a comprehensive handbook (LeeChiong T, ed), pp 49-61. Hoboken, New Jersey: Wiley.

Louie K, Wilson MA (2001) Temporally structured replay of awake hippocampal ensemble activity during rapid eye movement sleep. Neuron 29:145-156. CrossRef Medline

Marshall L, Born J (2007) The contribution of sleep to hippocampusdependent memory consolidation. Trends Cogn Sci 11:442-450. CrossRef Medline

Obrietan K, Impey S, Storm DR (1998) Light and circadian rhythmicity regulate MAP kinase activation in the suprachiasmatic nuclei. Nat Neurosci 1:693-700. CrossRef Medline

Paul S, Snyder GL, Yokakura H, Picciotto MR, Nairn AC, Lombroso PJ (2000) The dopamine/D1 receptor mediates the phosphorylation and inactivation of the protein tyrosine phosphatase STEP via a PKAdependent pathway. J Neurosci 20:5630-5638. Medline

Paul S, Nairn AC, Wang P, Lombroso PJ (2003) NMDA-mediated activation of the tyrosine phosphatase STEP regulates the duration of ERK signaling. Nat Neurosci 6:34-42. CrossRef Medline

Peigneux P, Laureys S, Delbeuck X, Maquet P (2001) Sleeping brain, learning brain: the role of sleep for memory systems. Neuroreport 12:A111-A124. CrossRef Medline

Phan TX, Phan TH, Chan GC, Sindreu CB, Eckel-Mahan KL, Storm DR (2011) The diurnal oscillation of MAP (mitogen-activated protein) kinase and adenylyl cyclase activities in the hippocampus depends on the suprachiasmatic nucleus. J Neurosci 31:10640-10647. CrossRef Medline

Pittenger C, Huang YY, Paletzki RF, Bourtchouladze R, Scanlin H, Vronskaya S, Kandel ER (2002) Reversible inhibition of CREB/ATF transcription factors in region CA1 of the dorsal hippocampus disrupts hippocampusdependent spatial memory. Neuron 34:447-462. CrossRef Medline

Pizzio GA, Hainich EC, Ferreyra GA, Coso OA, Golombek DA (2003) Circadian and photic regulation of ERK, JNK and p38 in the hamster SCN. Neuroreport 14:1417-1419. CrossRef Medline

Poe GR, Nitz DA, McNaughton BL, Barnes CA (2000) Experiencedependent phase-reversal of hippocampal neuron firing during REM sleep. Brain Res 855:176-180. CrossRef Medline

Rauchs G, Desgranges B, Foret J, Eustache F (2005) The relationships between memory systems and sleep stages. J Sleep Res 14:123-140. CrossRef Medline

Rechtschaffen A, Kales A (eds) (1968) A manual of standardized terminology, techniques and scoring system for sleep stages of human subjects. Bethesda, Maryland: U.S. National Institute of Neurological Diseases and Blindness, Neurological Information Network.
Roberson ED, English JD, Adams JP, Selcher JC, Kondratick C, Sweatt JD (1999) The mitogen-activated protein kinase cascade couples PKA and PKC to cAMP response element binding protein phosphorylation in area CA1 of hippocampus. J Neurosci 19:4337-4348. Medline

Shen J, Kudrimoti HS, McNaughton BL, Barnes CA (1998) Reactivation of neuronal ensembles in hippocampal dentate gyrus during sleep after spatial experience. J Sleep Res 7 [Suppl 1]:6-16.

Siegel JM (2008) Do all animals sleep? Trends Neurosci 31:208-213. CrossRef Medline

Siegel JM (2009) Sleep viewed as a state of adaptive inactivity. Nat Rev Neurosci 10:747-753. CrossRef Medline

Silva AJ, Kogan JH, Frankland PW, Kida S (1998) CREB and memory. Annu Rev Neurosci 21:127-148. CrossRef Medline

Sindreu CB, Scheiner ZS, Storm DR (2007) $\mathrm{Ca}^{2+}$ stimulated adenylyl cyclases regulate ERK-dependent activation of MSK1 during fear conditioning. Neuron 53:79-89. CrossRef Medline

Skaggs WE, McNaughton BL (1996) Replay of neuronal firing sequences in rat hippocampus during sleep following spatial experience. Science 271: 1870-1873. CrossRef Medline

Smith C (1996) Sleep states, memory processes and synaptic plasticity. Behav Brain Res 78:49-56. CrossRef Medline

Smith C, Rose GM (1996) Evidence for a paradoxical sleep window for place learning in the Morris water maze. Physiol Behav 59:93-97. CrossRef Medline

Smith CT, Conway JM, Rose GM (1998) Brief paradoxical sleep deprivation impairs reference, but not working, memory in the radial arm maze task. Neurobiol Learn Mem 69:211-217. CrossRef Medline

Stickgold R (1998) Sleep: off-line memory reprocessing. Trends Cogn Sci 2:484-492. CrossRef Medline

Stickgold R (2005) Sleep-dependent memory consolidation. Nature 437: 1272-1278. CrossRef Medline

Tobler I, Deboer T, Fischer M (1997) Sleep and sleep regulation in normal and prion protein-deficient mice. J Neurosci 17:1869-1879. Medline

Veasey SC, Valladares O, Fenik P, Kapfhamer D, Sanford L, Benington J, Bucan M (2000) An automated system for recording and analysis of sleep in mice. Sleep 23:1025-1040. Medline

Walker MP, Stickgold R (2004) Sleep-dependent learning and memory consolidation. Neuron 44:121-133. CrossRef Medline

Wang H, Ferguson GD, Pineda VV, Cundiff PE, Storm DR (2004) Overexpression of type- 1 adenylyl cyclase in mouse forebrain enhances recognition memory and LTP. Nat Neurosci 7:635-642. CrossRef Medline

Wilson MA, McNaughton BL (1994) Reactivation of hippocampal ensemble memories during sleep. Science 265:676-679. CrossRef Medline

Wong ST, Athos J, Figueroa XA, Pineda VV, Schaefer ML, Chavkin CC, Muglia LJ, Storm DR (1999) Calcium-stimulated adenylyl cyclase activity is critical for hippocampus-dependent long-term memory and late phase LTP. Neuron 23:787-798. CrossRef Medline

Wu ZL, Thomas SA, Villacres EC, Xia Z, Simmons ML, Chavkin C, Palmiter RD, Storm DR (1995) Altered behavior and long-term potentiation in type I adenylyl cyclase mutant mice. Proc Natl Acad Sci U S A 92:220224. CrossRef Medline

Xing J, Ginty DD, Greenberg ME (1996) Coupling of the RAS-MAPK pathway to gene activation by RSK2, a growth factor-regulated CREB kinase. Science 273:959-963. CrossRef Medline

Youngblood BD, Zhou J, Smagin GN, Ryan DH, Harris RB (1997) Sleep deprivation by the "flower pot" technique and spatial reference memory. Physiol Behav 61:249-256. CrossRef Medline

Zhang M, Storm DR, Wang H (2011) Bidirectional synaptic plasticity and spatial memory flexibility require $\mathrm{Ca}^{2+}$-stimulated adenylyl cyclases. J Neurosci 31:10174-10183. CrossRef Medline 